\title{
Neuroscience Research Using Non-human Primate Models and Genome Editing
}

\author{
Noriyuki Kishi and Hideyuki Okano
}

\begin{abstract}
The common marmoset (Callithrix jacchus) is a small New World non-human primate indigenous to northeastern Brazil. This species has been attracting the attention of biomedical researchers and neuroscientists for its ease of handling and colony maintenance, unique behavioral characteristics, and several human-like traits, such as enriched social vocal communication and strong relationships between parents and offspring. Its high reproductive efficiency makes it particularly amenable for use in the development of transgenic and genome editing technologies in a non-human primate model. Our group has recently generated transgenic marmosets with germ line transmission, opening new avenues in primate research.

In this chapter, we describe recent advances in neuroscience and disease research using common marmosets, and we outline potential uses of genome editing in non-human primates toward the development of knock-in/knock-out marmosets.
\end{abstract}

\section{Introduction}

Rodent models have long played important roles in neuroscience and medical research, made possible in part by the advent of robust genetic technologies. Knock-out/knock-in mouse models have shown particular utility in the neurosciences. There are nonetheless substantial anatomical, physiological, and cognitive differences between rodents and humans. The human brain consists of two major functional domains, one that is evolutionarily conserved and a second that is primate-specific and the locus of many higher cognitive functions. For many human neurological and psychiatric diseases involving higher cognitive dysfunctions, studies using rodent models may thus not be informative with respect to the relevant pathophysiological mechanisms. To gain a better understanding of the

\footnotetext{
N. Kishi • H. Okano $(\bowtie)$

Laboratory for Marmoset Neural Architecture, RIKEN Brain Science Institute, 2-1 Hirosawa, Wako-shi, Saitama 351-0198, Japan

Department of Physiology, Keio University School of Medicine, 35 Shinanomachi, Shinjukuku, Tokyo 160-8582, Japan

e-mail: hidokano@a2.keio.jp
} 
pathogenesis of such diseases, we need animal models that exhibit brain functions more closely similar to those in humans.

This need has led to increased interest in the development of genetically engineered non-human primates for use in the study of both functional domains. Our group has recently generated a transgenic common marmoset, a New World monkey (Sasaki et al. 2009). Emerging genome editing techniques are also opening new possibilities for the creation of better non-human primate models for use in the study of neurodegenerative and mental disorders (Izpisua Belmonte et al. 2015).

This chapter is an updated and modified version of previously published review articles on marmosets (Okano et al. 2016; Kishi et al. 2014) and work presented by Hideyuki Okano at the "Genome Editing in Neurosciences" symposium.

\section{Characteristics of the Common Marmoset}

Common marmosets (Callithrix jacchus) are New World primates native to the Atlantic coastal forests of northeastern Brazil (Abbott et al. 2003; Carrion and Patterson 2012; Mansfield 2003; Okano et al. 2016; Tokuno et al. 2012; Kishi et al. 2014; Izpisua Belmonte et al. 2015). These small monkeys (adult height: $20-30 \mathrm{~cm}$; weight: $350-400 \mathrm{~g}$ ) have ear tufts and relatively long banded tails, and they are omnivorous, eating plant exudates, lizards, and infant mammals. Common marmosets are monogamous and, unlike many other non-human primates, live in stable families of approximately ten members (Tardif et al. 2003). Females commonly give birth to two babies per litter and are ready to breed again about 10 days after giving birth; they typically have two litters per year. Since mothers need to nurse infants during gestation and the perinatal period, the male partner and other members of the group also provide infant care. This remarkably human-like trait is a focus of attention among neuroscientists and behavioral scientists.

Although common marmosets have been used for biomedical research since the 1960s, macaque monkeys are more widely used in research, due to their closer similarity to humans. The recent rapid advances in genome editing are now calling new attention to the advantages offered by the marmoset because of its size, availability, and high reproductivity.

Macaques are evolutionarily closer to humans than common marmosets, but some marmoset traits are more similar to those of humans, perhaps due either to geographical segregation or convergent evolution. New World primates are estimated to have diverged from Old World primates 35 mya, and these monkeys have adapted to neotropical environments. Despite this phylogenetic distance, common marmosets, like humans, exhibit strong intergenerational kin relationships and social vocal communications (Dell'Mour et al. 2009; Eliades and Wang 2008; Gordon and Rogers 2010), which may indicate a convergent trajectory in their evolution. The genomic basis of the origins of such traits may be addressable through genome editing studies in the future. 


\section{Advantages of Using Common Marmosets for Biomedical Research}

Rodents play a crucial role in biomedical investigations in many research fields. Powerful genetic tools, such as knock-out/knock-in mice, have informed the study of gene functions, but the significant anatomical and physiological differences between rodents and humans mean that a more closely similar animal model is needed to advance our understanding of human biology in areas such as the neurosciences.

For biomedical use, the common marmoset offers many advantages. Marmoset endocrinology and metabolism are more similar to those of humans than of rodents, which is important in pharmacological and toxicological studies of new drug candidates. The marmoset is also more closely phylogenetically related to humans (Kitamura et al. 2011; t'Hart et al. 2003, 2012). In Europe, the marmoset is now being used as a non-rodent second species in drug safety tests (Smith et al. 2001).

The common marmoset can be handled with greater ease than many other non-human primates. Along with the appropriateness of the model to the research question, animal welfare and availability are important factors in selecting a model species. Marmosets are readily obtained for laboratory use and, as distinct from macaques, have not been reported to carry herpes b virus (Macacine herpesvirus 1), providing a safety benefit to researchers and animal facility staff (Mansfield 2003). The small size of marmosets is also beneficial as it reduces costs and floor space requirements (Smith et al. 2001).

Common marmosets are among the most highly reproductive of all primates. The ovarian cycle is approximately 28 days, similar to that in human (Summers et al. 1985). The gestation period is approximately 145-148 days. Female animals are ready to breed again 10 days after delivery. Usually, female marmosets have two litters per year, which is strongly advantageous when compared to macaques, which require 5 years to sexual maturation and breed only once per year (Austad and Fischer 2011). The remarkable reproductive efficiency of marmosets is extremely well-suited to the development of transgenic and genome editing techniques.

Lastly, a number of basic research tools have been developed for use in marmosets, which is important for encouraging broader adoption by the scientific community. Although the annotated sequencing of its genome has not been completed, a draft sequence with $6 \times$ coverage using whole-genome shotgun sequencing is available on GenBank (The Marmoset Genome Sequencing and Analysis Consortium 2014; URL: https://www.hgsc.bcm.edu/content/marmoset-genome-project).

Our group has also sequenced the marmoset genome using animals from the colony maintained by the Central Institute for Experimental Animals (CIEA) in Kawasaki, Japan (Sato et al. 2015). Resequencing and assembly of the genome were performed by deep sequencing with high-throughput sequencing technology using a next-generation sequencer, giving approximately $60 \times$ coverage. This 
enabled us to generate genome assemblies and gene-coding sequence analysis more efficiently and provided a basis for genome editing.

We have also applied non-invasive imaging methods in marmoset research. The use of marmosets in such studies is limited to small numbers due to cost and ethical issues. Magnetic resonance imaging (MRI) is a non-invasive imaging technique to visualize various organs in detail. We have adapted a number of MRI techniques, including diffusion tensor tractography (DTT; Fujiyoshi et al. 2007; Hikishima et al. 2015) and voxel based morphometric (VBM) analysis (Hikishima et al. 2011, 2015), and a new method for the visualization of myelin (Myelin Map; Fujiyoshi et al. 2016).

\section{Transgenic Techniques and Genome Editing Technology for Marmoset Research}

One of the strengths of the mouse model is the availability of powerful genetic tools, such as transgenic and knock-in/knock-out animals, that have given the mouse a central place in life sciences research over the past two decades. However, results from mouse genetics are not always directly relevant to humans. Particularly in the neurosciences, there are considerable interspecies differences in brain anatomy and physiology, behavioral control mechanisms, and life span, and some mouse disease models do not recapitulate human symptoms. For example, neurofibrillary tangles, the neuropathological hallmarks of Alzheimer's disease, cannot be recapitulated in mice showing amyloid plaques (Chin 2011; Games et al. 1995; Hsiao et al. 1996; Sturchler-Pierrat et al. 1997; Tanzi and Bertram 2005; Walsh and Selkoe 2004). It is also known that mice in which parkin, the gene associated with familial Parkinson's disease in humans, has been knocked out do not show parkinsonism.

Despite the scientific demand for research in non-human primates, efforts to generate transgenic non-human primate animals have been unsuccessful until recently. In 2008, Yang et al. (2008) reported a transgenic rhesus macaque expressing the human huntingtin (HTT) gene with a CAG-expansion encoding the poly glutamine as a model of Huntington's disease. However, despite the genomic insertion of the human HTT-transgene in the founder monkeys, germline transmission of the transgene has not been confirmed. Our group independently generated transgenic common marmosets expressing the enhanced GFP (EGFP) gene and we reported the first germline transmission in a non-human primate (Sasaki et al. 2009).

While the establishment of transgenic marmosets enables the generation of marmoset models of diseases caused by overexpression of a relatively small mutant gene, such as Parkinson's disease, Alzheimer's disease, and amyotrophic lateral sclerosis (ALS), transgenic techniques limited our ability to genetically modify non-human primates. Transgenic technologies available at the time could only randomly insert only $<8 \mathrm{~kb}$ of exogenous genes into the genome (Sasaki et al. 2009). Moreover, 
transgenes were segregated and suppressed across generations, expression levels could not be controlled, and the techniques were only suited to gain-of-function, not loss-of function, studies. Most human genetic diseases are caused by either point mutations or deletions of endogenous genes, which highlighted the need for new gene modification technologies for use against endogenous genes.

Remarkable recent advances in genome editing technology have now made it possible to overcome these previous limitations (Sato et al. 2016). Genome editing tools, i.e., engineered nucleases, bind to a target genome sequence and introduce specific double-strand breaks. Double-strand breaks initiate cell-endogenous repair mechanisms such as homology-directed repair (HDR), non-homologous end-joining (NHEJ), and microhomology-mediated end-joining (MMEJ). Mutagenesis against endogenous genes can be introduced by taking advantage of such mechanisms. Zinc finger nucleases (ZFNs), transcription activator-like effector nucleases (TALENs), and the clustered regularly interspaced short palindromic repeat (CRISPR)/Cas system are mainly used as engineered nucleases. A number of genetically modified animals have already been generated using such restriction enzymes (Bedell et al. 2012; Geurts et al. 2009; Hauschild et al. 2011; Mashimo et al. 2010; Ochiai et al. 2010; Sung et al. 2013; Suzuki et al. 2013; Wang et al. 2013; Yang et al. 2013). Among these, the CRISPR/Cas system was developed the most recently and is particularly promising (Cong et al. 2013; Mali et al. 2013).

Using these genome editing technologies, we recently generated X-linked SCID model marmosets by knock-out of interleukin- 2 receptor subunit gamma gene (Sato et al., 2016). Currently, we are now seeking to generate marmoset models of autism spectrum disorders, including Rett syndrome (Chahrour and Zoghbi 2007; Kishi and Macklis 2005) and tuberous sclerosis complex (Ess 2010; Fig. 1). Although a mouse model (male hemizygous MecP2 mutation) is available for Rett syndrome, it does not necessarily mimic the critical symptoms. For example, while male hemizygous mice (Mecp2-/y) are used as model mice, Rett patients are exclusively female heterozygous in human. It is likely that males with MECP2 mutations are embryonic lethal in human, but not in mice. Furthermore, phenotypes appear at adult stages in mouse models, whereas symptoms become evident by 1 year of age in human Rett syndrome patients. New primate models that more closely mimic the
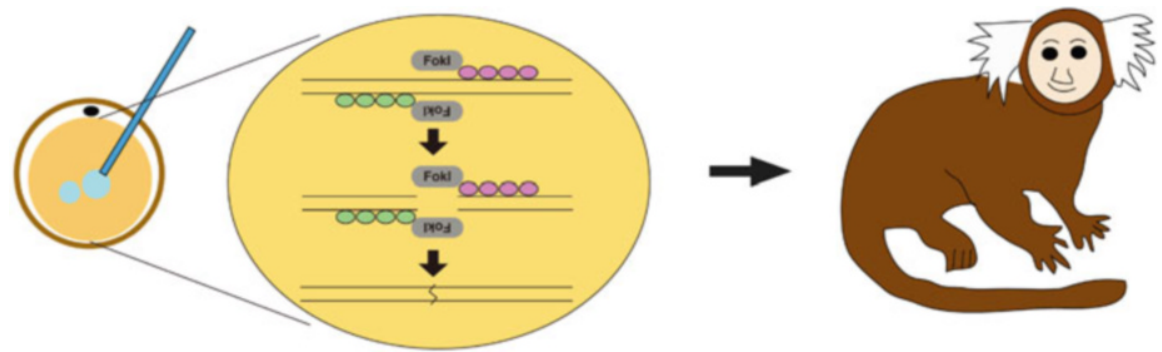

Fig. 1 Generation of a knock-out marmoset by genome editing with ZFN or TALEN 
clinical course of human disease may thus contribute to a better understanding of the pathogenesis and future treatments for neurodevelopmental disorders.

\section{Future Perspectives}

Genome editing has developed rapidly in recent years, leading to the production of genetically modified animals in many species. This technology has also been applied to non-human primates, and some groups have begun to report genetically modified macaques (Niu et al. 2014; Liu et al. 2014). Macaques offer a number of advantages, but it is difficult to expand colony size within a reasonable research period. We suggest that the common marmoset is thus a highly suitable alternative model primate for many areas of study, and the creation of knock-in/knock-out marmosets would help to introduce the benefits of this model to a larger community of researchers. Since germ-line-competent marmoset embryonic stem cells are not currently available, it is necessary to perform genome editing in one-cell stage embryos (fertilized eggs) to obtain knock-in/knock-out marmosets efficiently. The emergence of more sophisticated genome editing techniques will facilitate and accelerate the development of new gene manipulation technologies in marmoset. Marmoset models of disease generated using genome editing may contribute to the development of new therapeutic strategies for currently incurable neurodegenerative diseases and mental disorders.

Acknowledgments This work was supported by a grant from Brain Mapping by Integrated Neurotechnologies for Disease Studies (Brain/MINDS) from the Ministry of Education, Culture, Sports, Science, and Technology of Japan (MEXT) and the Japan Agency for Medical Research and Development (A-MED).

\section{References}

Abbott DH, Barnett DK, Colman RJ, Yamamoto ME, Schultz-Darken NJ (2003) Aspects of common marmoset basic biology and life history important for biomedical research. Comp Med 53:339-350

Austad SN, Fischer KE (2011) The development of small primate models for aging research. ILAR J/National Research Council, Institute of Laboratory Animal. Resources 52:78-88

Bedell VM, Wang Y, Campbell JM, Poshusta TL, Starker CG, Krug RG 2nd, Tan W, Penheiter SG, Ma AC, Leung AY, Fahrenkrug SC, Carlson DF, Voytas DF, Clark KJ, Essner JJ, Ekker SC (2012) In vivo genome editing using a high-efficiency TALEN system. Nature 491:114-118

Carrion R Jr, Patterson JL (2012) An animal model that reflects human disease: the common marmoset (Callithrix jacchus). Curr Opin Virol 2:357-362

Chahrour M, Zoghbi HY (2007) The story of Rett syndrome: from clinic to neurobiology. Neuron $56: 422-437$

Chin J (2011) Selecting a mouse model of Alzheimer's disease. Methods Mol Biol 670:169-189 
Cong L, Ran FA, Cox D, Lin S, Barretto R, Habib N, Hsu PD, Wu X, Jiang W, Marraffini LA, Zhang F (2013) Multiplex genome engineering using CRISPR/Cas systems. Science 339:819-823

Dell'Mour V, Range F, Huber L (2009) Social learning and mother's behavior in manipulative tasks in infant marmosets. Am J Primatol 71:503-509

Eliades SJ, Wang X (2008) Neural substrates of vocalization feedback monitoring in primate auditory cortex. Nature 453:1102-1106

Ess KC (2010) Tuberous sclerosis complex: a brave new world? Curr Opin Neurol 23:189-193

Fujiyoshi K, Yamada M, Nakamura M, Yamane J, Katoh H, Kitamura K, Kawai K, Okada S, Momoshima S, Toyama Y, Okano H (2007) In vivo tracing of neural tracts in the intact and injured spinal cord of marmosets by diffusion tensor tractography. J Neurosci 27:11991-11998

Fujiyoshi K, Hikishima K, Nakahara J, Tsuji O, Hata J, Konomi T, Nagai T, Shibata S, Kaneko S, Iwanami A, Momoshima S, Takahashi S, Jinzaki M, Suzuki N, Toyama Y, Nakamura M, Okano $\mathrm{H}$ (2016) Application of q-Space diffusion MRI for the visualization of white matter. J Neurosci 36:2796-2808

Games D, Adams D, Alessandrini R, Barbour R, Berthelette P, Blackwell C, Carr T, Clemens J, Donaldson T, Gillespie F, Guido T, Hagopian S, Johnson-Wood K, Khan K, Lee M, Leibowitz P, Lieberburg I, Little S, Masliah E, McConlogue L, Montoya-Zavala M, Mucke L, Paganini L, Penniman E, Power M, Schenk D, Seubert P, Snyder B, Soriano F, Tan H, Vitale J, Wadsworth S, Wolozin B, Zhao J (1995) Alzheimer-type neuropathology in transgenic mice overexpressing V717F beta-amyloid precursor protein. Nature 373:523-527

Geurts AM, Cost GJ, Freyvert Y, Zeitler B, Miller JC, Choi VM, Jenkins SS, Wood A, Cui X, Meng X, Vincent A, Lam S, Michalkiewicz M, Schilling R, Foeckler J, Kalloway S, Weiler H, Menoret S, Anegon I, Davis GD, Zhang L, Rebar EJ, Gregory PD, Urnov FD, Jacob HJ, Buelow R (2009) Knockout rats via embryo microinjection of zinc-finger nucleases. Science 325:433

Gordon DJ, Rogers LJ (2010) Differences in social and vocal behavior between left- and righthanded common marmosets (Callithrix jacchus). J Comp Psychol 124:402-411

Hauschild J, Petersen B, Santiago Y, Queisser AL, Carnwath JW, Lucas-Hahn A, Zhang L, Meng X, Gregory PD, Schwinzer R, Cost GJ, Niemann H (2011) Efficient generation of a biallelic knockout in pigs using zinc-finger nucleases. Proc Natl Acad Sci USA 108:12013-12017

Hikishima K, Quallo MM, Komaki Y, Yamada M, Kawai K, Momoshima S, Okano HJ, Sasaki E, Tamaoki N, Lemon RN, Iriki A, Okano H (2011) Population-averaged standard template brain atlas for the common marmoset (Callithrix jacchus). Neuroimage 54:2741-2749

Hikishima K, Ando K, Komaki Y, Kawai K, Yano R, Inoue T, Itoh T, Yamada M, Momoshima S, Okano HJ, Okano H (2015) Voxel-based morphometry of the marmoset brain: in vivo detection of volume loss in the substantia nigra of the MPTP-treated Parkinson's disease model. Neuroscience 300:585-592

Hsiao K, Chapman P, Nilsen S, Eckman C, Harigaya Y, Younkin S, Yang F, Cole G (1996) Correlative memory deficits, Abeta elevation, and amyloid plaques in transgenic mice. Science 274:99-102

Izpisua Belmonte JC, Callaway EM, Caddick SJ, Churchland P, Feng G, Homanics GE, Lee KF, Leopold DA, Miller CT, Mitchell JF, Mitalipov S, Moutri AR, Movshon JA, Okano H, Reynolds JH, Ringach D, Sejnowski TJ, Silva AC, Strick PL, Wu J, Zhang F (2015) Brains, genes, and primates. Neuron 86:617-631

Kishi N, Macklis JD (2005) Dissecting MECP2 function in the central nervous system. J Child Neurol 20:753-759

Kishi N, Sat K, Sasaki E, Okano H (2014) Common marmoset as a new model animal for neuroscience research and genome editing technology. Dev Growth Differ 56:53-62

Kitamura K, Fujiyoshi K, Yamane J, Toyota F, Hikishima K, Nomura T, Funakoshi H, Nakamura T, Aoki M, Toyama Y, Okano H, Nakamura M (2011) Human hepatocyte growth factor promotes functional recovery in primates after spinal cord injury. PLoS One 6:e27706 
Liu H, Chen Y, Niu Y, Zhang K, Kang Y, Ge W, Liu X, Zhao E, Wang C, Lin S, Jing B, Si C, Lin Q, Chen X, Lin H, Pu X, Wang Y, Qin B, Wang F, Wang H, Si W, Zhou J, Tan T, Li T, Ji S, Xue Z, Luo Y, Cheng L, Zhou Q, Li S, Sun YE, Ji W (2014) TALEN-mediated gene mutagenesis in rhesus and cynomolgus monkeys. Cell Stem Cell 14:323-328

Mali P, Yang L, Esvel KM, Aach J, Guell M, DiCarlo JE, Norville JE, Church GM (2013) RNA-guided human genome engineering via Cas9. Science 339:823-826

Mansfield K (2003) Marmoset models commonly used in biomedical research. Comp Med 53:383-392

Mashimo T, Takizawa A, Voigt B, Yoshimi K, Hiai H, Kuramoto T, Serikawa T (2010) Generation of knockout rats with X-linked severe combined immunodeficiency (X-SCID) using zincfinger nucleases. PLoS One 5:e8870

Niu Y, Shen B, Cui Y, Chen Y, Wang J, Wang L, Kang Y, Zhao X, Si W, Li W, Xiang AP, Zhou J, Guo X, Bi Y, Si C, Hu B, Dong G, Wang H, Zhou Z, Li T, Tan T, Pu X, Wang F, Ji S, Zhou Q, Huang X, Ji W, Sha J (2014) Generation of gene-modified cynomolgus monkey via Cas9/ RNA-mediated gene targeting in one-cell embryos. Cell 156:836-843

Ochiai H, Fujita K, Suzuki K, Nishikawa M, Shibata T, Sakamoto N, Yamamoto T (2010) Targeted mutagenesis in the sea urchin embryo using zinc-finger nucleases. Genes Cells 15:875-885

Okano H, Sasaki E, Yamamori T, Iriki A, Shimogori T, Yamaguchi Y, Kasai K, Miyawaki A (2016) Brain/MINDS: a Japanese National Brain Project for Marmoset Neuroscience. Neuron 92:582-590

Sasaki E, Suemizu H, Shimada A, Hanazawa K, Oiwa R, Kamioka M, Tomioka I, Sotomaru Y, Hirakawa R, Eto T, Shiozawa S, Maeda T, Ito M, Ito R, Kito C, Yagihashi C, Kawai K, Miyoshi H, Tanioka Y, Tamaoki N, Habu S, Okano H, Nomura T (2009) Generation of transgenic non-human primates with germline transmission. Nature 459:523-527

Sato K, Kuroki Y, Kumita W, Fujiyama A, Toyoda A, Kawai J, Iriki A, Sasaki E, Okano H, Sakakibara Y (2015) Resequencing of the common marmoset genome assemblies and genecoding sequence analysis. Sci Rep 5:16894

Sato K, Oiwa R, Kumita W, Henry R, Sakuma T, Ito R, Nozu R, Inoue T, Katano I, Sato K, Okahara N, Okahara J, Shimizu Y, Yamamoto M, Hanazawa K, Kawakami T, Kametani Y, Ryuji Suzuki R, Takahashi T, Weinstein EJ, Yamamoto T, Sakakibara Y, Habu S, Hata J, Okano H, Sasaki E (2016) Generation of a nonhuman primate model of severe combined immunodeficiency using highly efficient genome editing. Cell Stem Cell 19:127-138

Smith D, Trennery P, Farningham D, Klapwijk J (2001) The selection of marmoset monkeys (Callithrix jacchus) in pharmaceutical toxicology. Lab Anim 35:117-130

Sturchler-Pierrat C, Abramowski D, Duke M, Wiederhold KH, Mistl C, Rothacher S, Ledermann B, Burki K, Frey P, Paganetti PA, Waridel C, Calhoun ME, Jucker M, Probst A, Staufenbiel M, Sommer B (1997) Two amyloid precursor protein transgenic mouse models with Alzheimer disease-like pathology. Proc Natl Acad Sci USA 94:13287-13292

Summers PM, Wennink CJ, Hodges JK (1985) Cloprostenol-induced luteolysis in the marmoset monkey (Callithrix jacchus). J Reprod Fertil 73:133-138

Sung YH, Baek IJ, Kim DH, Jeon J, Lee J, Lee K, Jeong D, Kim JS, Lee HW (2013) Knockout mice created by TALEN-mediated gene targeting. Nat Biotechnol 31:23-24

Suzuki KT, Isoyama Y, Kashiwagi K, Sakuma T, Ochiai H, Sakamoto N, Furuno N, Kashiwagi A, Yamamoto T (2013) High efficiency TALENs enable F0 functional analysis by targeted gene disruption in Xenopus laevis embryos. Biol Open 2:448-452

t'Hart BA, Vervoordeldonk M, Heeney JL, Tak PP (2003) Gene therapy in nonhuman primate models of human autoimmune disease. Gene Ther 10:890-901

t'Hart BA, Abbott DH, Nakamura K, Fuchs E (2012) The marmoset monkey: a multi-purpose preclinical and translational model of human biology and disease. Drug Discov Today $17: 1160-1165$

Tanzi RE, Bertram L (2005) Twenty years of the Alzheimer's disease amyloid hypothesis: a genetic perspective. Cell 120:545-555 
Tardif SD, Smucny DA, Abbott DH, Mansfield K, Schultz-Darken N, Yamamoto ME (2003) Reproduction in captive common marmosets (Callithrix jacchus). Comp Med 53:364-368

The Marmoset Genome Sequencing and Analysis Consortium (2014) The common marmoset genome provides insight into primate biology and evolution. Nat Genet 46:850-857

Tokuno H, Moriya-Ito K, Tanaka I (2012) Experimental techniques for neuroscience research using common marmosets. Experimental animals/Japanese Association for. Lab Anim Sci 61:389-397

Walsh DM, Selkoe DJ (2004) Deciphering the molecular basis of memory failure in Alzheimer's disease. Neuron 44:181-193

Wang H, Yang H, Shivalila CS, Dawlaty MM, Cheng AW, Zhang F, Jaenisch R (2013) One-step generation of mice carrying mutations in multiple genes by CRISPR/Cas-mediated genome engineering. Cell 153:910-918

Yang SH, Cheng PH, Banta H, Piotrowska-Nitsche K, Yang JJ, Cheng EC, Snyder B, Larkin K, Liu J, Orkin J, Fang ZH, Smith Y, Bachevalier J, Zola SM, Li SH, Li XJ, Chan AW (2008) Towards a transgenic model of Huntington's disease in a non-human primate. Nature 453:921-924

Yang H, Wang H, Shivalila CS, Cheng AW, Shi L, Jaenisch R (2013) One-step generation of mice carrying reporter and conditional alleles by CRISPR/Cas-mediated genome engineering. Cell 154:1370-1379

Open Access This chapter is licensed under the terms of the Creative Commons Attribution 4.0 International License (http://creativecommons.org/licenses/by/4.0/), which permits use, sharing, adaptation, distribution and reproduction in any medium or format, as long as you give appropriate credit to the original author(s) and the source, provide a link to the Creative Commons license and indicate if changes were made.

The images or other third party material in this chapter are included in the chapter's Creative Commons license, unless indicated otherwise in a credit line to the material. If material is not included in the chapter's Creative Commons license and your intended use is not permitted by statutory regulation or exceeds the permitted use, you will need to obtain permission directly from the copyright holder.

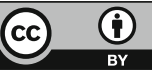

